\title{
Feminismos, Masculinidades Transexualidade
}

Gênero em termos reais.

CONNELL, Raewyn.

Trad. de Marília Moschovich, São Paulo: nVersos, 2016.

Em um momento de considerável efervescência do debate político e acadêmico a respeito de gênero e feminismo, autoras como Raewyn Connell trazem importantes contribuições. Publicado pela nVersos, em 2016, Gênero em termos reais apresenta uma série de artigos publicados pela autora ao longo de sua carreira. Dividido em três partes "Dinâmicas do gênero", "Homens e Masculinidades", "Mulheres Transexuais" -, o livro explicita uma abordagem mais abrangente e plural acerca do conceito de gênero, isto é, não se restringindo apenas aos estudos sobre mulheres "cis" (aquelas identificadas biológica e socialmente com o gênero feminino).

Curiosamente, estes três pilares que o compõem dizem respeito a temas polêmicos da agenda de pesquisa contemporânea sobre gênero e feminismo. Ademais, ressalta-se que ainda que careça de uma revisão mais cuidadosa da tradução, a leitura é fluida e relativamente acessível. Isso se dá também em razão da nota da tradutora que integra o início da obra, promovendo uma elucidação do campo e de conceitos utilizados no decorrer do livro.

Australiana, nascida em 1944, a partir da década de 1970 Connell atuou como professora de sociologia, pesquisando inicialmente as dinâmicas de classe. Nos anos 1980, iniciou sua incursão nos estudos de gênero a partir de uma perspectiva que considera gênero como uma categoria estruturante, não sendo reduzido somente às questões identitárias. Posteriormente, Connell passou a ser reconhecida como uma das pesquisadoras pioneiras sobre masculinidades. Sua vida pessoal é um caso à parte, pois desde os anos 2000 ela vive como uma mulher transexual. Essa informação, de cunho pessoal, talvez não valesse a menção, mas é um item que se relaciona à sua trajetória acadêmica e a suas investigações recentes sobre transexualidade.

Por ser também uma importante referência nas pesquisas sobre Teorias do Sul, no primeiro capítulo, "Colonialidade do gênero", a autora busca promover diálogos sobre gênero em consonância com perspectivas críticas acerca da teoria descolonial e da 
geopolítica do conhecimento. O colonialismo assume, então, uma característica central em suas análises, uma vez que ele "é em si uma fonte massiva de dinâmicas sociais" (Raewyn CONNELL, 2016, p. 25).

Quando pautadas, as experiências das mulheres do terceiro mundo' resultam numa abordagem interseccional que costuma mobilizar aspectos de gênero, raça, classe e nacionalidade. Em virtude disso, faz-se necessário apropriar-se de múltiplas referências, valendo-se de certo ecletismo epistemológico, pois "nem uma revolução de classe e nem o fim da colonização encerram as injustiças de gênero" (CONNELL, 2016, p. 31). Ainda que o feminismo ocidental seja um aporte relativamente heterodoxo, ele eventualmente se furta (ou é incapaz) de compreender, segundo a autora, que "as dinâmicas de gênero tomam formas específicas em contextos coloniais e pós-coloniais, pois, como aponta Lugones (2007), estão entrelaçadas às dinâmicas de colonização e globalização (ldem)" (CONNELL, 2016, p. 31). Além disso, sublinha que no encontro colonial, as masculinidades, sobretudo dos colonizados, também sofreram alterações, sendo este um tema abordado no sétimo capítulo.

Ainda que as distinções pontuadas sejam significativas em termos geopolíticos entre homens e mulheres submetidos/reprodutores ao colonialismo, a autora faz uso das nomenclaturas de Sul e Norte Global de uma forma simplória. Por conta de sua nacionalidade, Connell ilustra uma série de comentários tomando a Austrália como referência e vinculando-a à periferia global. A associação deste país ao Sul Global toma como critério seu passado colonial. Em razão disso, como já foi apontado por críticos do pós-colonialismo, ela acaba por reproduzir determinados equívocos conceituais, assumindo uma categorização acrítica em termos de hierarquização geopolítica (Ella SHOHAT, 1992). Comparando, por exemplo, Estados Unidos e Bolívia, ambos foram colonizados e possuem políticas e dinâmicas de gênero distintas. Assim, o emprego do termo "Sul Global" obscurece outras relações de poder, como imperialismo e neocolonialismo, que se manifestam de forma sistêmica, e impulsionados pela globalização neoliberal.

No capítulo seguinte, "Os corpos do Sul e as deficiências", Connell desenvolve um raciocínio tumultuado acerca da corporificação social. Ela pretende demonstrar a maneira como a colonização, o capitalismo e o patriarcado impactam nas relações sociais e de gênero, de modo a oprimir, regular e marginalizar os corpos, evidenciando uma "'coconstrução' do biológico com o social" (CONNELL, 2016, p. 48). Ela pauta questões relativas à exploração do trabalho, reprodução sexual, deficiência física e indústrias pornográfica e de beleza. No entanto, ela o faz de forma confusa e pouco desenvolvida, comprometendo, assim, uma melhor compreensão sobre o assunto.

Em "Como os regimes de gênero mudam dentro do Estado", terceiro capítulo do livro, a autora investiga como as relações de gênero são estabelecidas nas instituições estatais, uma vez que, como agências públicas, esses setores desempenham um papel importante na promoção da igualdade de gênero. De modo geral, como demonstram as entrevistas realizadas pela autora, os inqueridos tratam gênero como um "não problema", isto é, uma temática superada. No entanto, Connell observa que quando ocorre algum tipo de assédio ou discriminação de gênero, tais episódios são vinculados à esfera individual, sendo uma questão de comportamento pessoal, não um estilo de administração pública. Nesse caso, a autora assevera corretamente que a suposta neutralidade de gênero assumida nas entrevistas demonstra ser a única maneira viável de se pensar o tema da igualdade diante

\footnotetext{
I Sabe-se que há problematizações acerca das nomenclaturas "Sul Global" e "Terceiro Mundo" como foi exposto por Ella Shohat (1992). No entanto, acreditando não haver prejuízos na interpretação do texto, nesta resenha estas duas categorias são empregadas como sinônimos.
} 
do neoliberalismo crescente - que se assenta na postura e ética individuais, deixando intocáveis as estruturas do sistema. Nesse contexto, debates sobre a divisão de trabalho de gênero, por exemplo, sequer podem ser aprofundados.

Inaugurando a segunda seção do livro, Connell inicia o quarto capítulo "Os controladores de acesso mudam: homens, masculinidades e igualdade de gênero" com o seguinte questionamento: "eles [os homens] estão dispostos a abrir as portas?" (CONNELL, 2016, p. 91). Embora a discussão acerca de masculinidades seja um tópico necessário, esta pergunta pouco auxilia para a compreensão da temática. Por mais que homens também sejam afetados pelas dinâmicas de gênero, o posicionamento deles na luta pela igualdade é, certamente, uma pauta conflituosa nos movimentos feministas.

A autora, no entanto, traz uma contribuição importante: "Fica claro que, globalmente, os homens têm muito a perder ao lutar pela igualdade de gênero porque os homens, coletivamente, continuam a coletar dividendos patriarcais" (CONNELL, 2016, p. 98). De acordo com a pesquisadora, isso significa que "as desvantagens são, de modo geral, as condições das vantagens" (CONNELL, 2016, p. 99). Essas assertivas exemplificam o fato de que a luta pela igualdade exige políicas públicas de gênero e diálogo com os movimentos feministas, não sendo, portanto, uma questão de gentileza e abdicação voluntária de privilégios.

Connell aponta a maneira como alguns homens mudam de comportamento após o nascimento de suas filhas, sendo um motivo para ser otimista frente a uma sociedade menos misógina. Depender da benevolência de homens dispostos a rever suas atitudes e comportamentos não pode ser motivo de otimismo pois o compromisso com a igualdade de gênero não deve restringir-se a uma questão pessoal. A autora finaliza afirmando que o conceito de aliança entre homens e mulheres, na defesa da e pela igualdade de gênero, é uma estratégia importante para que se mantenha o protagonismo feminino ao mesmo tempo em que convida os homens a se engajarem pela causa.

Nos dois capítulos seguintes, Connell atenta para as masculinidades em duas ocasiões, respectivamente: na vida corporativa dos "homens de negócio" e do "crescer como masculino" durante a adolescência. De acordo com a autora, há desvantagens nessas duas ocasiões que demonstram que a opressão de gênero é algo que não acomete somente mulheres. Espera-se que os homens, sobretudo os que vivenciam o ambiente corporativo, sejam competitivos e provedores financeiros de suas famílias. Em razão dessa pressão, os executivos costumam sofrer de esgotamento físico, ansiedade e demais problemas de saúde. Os meninos, por sua vez, são estimulados a adotarem comportamentos violentos, a reprimirem sentimentos, a terem uma vida sexual ativa e heteronormativa.

Ainda nesse sentido, a autora menciona, embora pouco enfática, que essas situações onerosas vivenciadas por homens e meninos são condicionadas pela depreciação daquilo que é considerado feminino e pela posição subalterna que as mulheres ocupam na sociedade. Por exemplo, o que permite homens de negócios dedicarem-se ao trabalho são mulheres (suas companheiras ou domésticas) que assumem a tarefa de administrar o lar. Já os meninos são impedidos de demonstrar inseguranças e sentimentos, pois tais características são associadas, pejorativamente, às mulheres. Dessa maneira, os apontamentos que Connell faz acerca das masculinidades e da igualdade de gênero poderiam ter contado com uma abordagem mais crítica acerca da misoginia que, para além dos estereótipos, é violenta e incide principalmente no corpo das mulheres.

Em "Perspectivas do Norte e do Sul sobre a masculinidade", Connell demonstra que, similar à categoria mulheres, a categoria "homens" é também heterogênea, de modo que uma parte deles não se vê representada pela figura branca, heterossexual e ocidental que se encontra no topo da hierarquia social. A autora relembra que os estudos acerca das 
masculinidades foram institucionalizados a partir de 1985, no entanto, há registros predecessores, da década de 1950, referentes aos homens em relação ao imperialismo e ao colonialismo que na época não foram reconhecidos.

É o caso de, por exemplo, Frantz Fanon com o seu controverso Pele negra, máscaras brancas no qual analisa como o colonialismo e o imperialismo afetam as pessoas negras, especificamente homens. A autora considera que "o livro também é uma análise das masculinidades brancas e negras, e de suas relações dentro do colonialismo e da cultura racista" (CONNELL, 2016, p. 171). Apesar das polêmicas em relação à representação das mulheres, Fanon faz uma análise lúcida do colonialismo como sendo um "sistema de violência e de exploração econômica; as consequências psicológicas advêm de relações materiais" (CONNELL, 2016, p. 171). Dessa forma, compreende-se que a experiência colonial coisifica e animaliza os homens negros que, em virtude da suposta inferioridade ratificada pela "biologia" e pelo "discurso científico", produz uma série de alienações que impactam o colonizado.

No fim da década de 1980, período anterior à sua transição, Connell foi contatada por Robyn (nome fictício), uma mulher trans que se ofereceu para ser entrevistada. Sua história de vida e as observações que a autora faz a respeito integram o oitavo capítulo denominado "Duas latas de tinta, história de vida de uma pessoa transexual". Inicialmente, as referências da entrevistada acerca do que era considerado feminino incomodou Connell por significarem uma noção estereotipada ${ }^{2}$ das mulheres. Esse é um ponto muito "caro" na controvérsia entre algumas feministas e mulheres transexuais, e a autora não nega as contradições: se órgão sexual não define gênero, tampouco usar vestidos e sapatos de salto definiriam. Ela reconhece que a transexualidade por si só é "politicamente neutra" (CONNELL, 2016, p. 198) e, por vezes, despolitizada. Dessa maneira, ela considera que não há um caminho para a justiça e à igualdade de gênero que não seja através dos movimentos feministas. Somente a partir do debate se podem vislumbrar alternativas e contrair novas "possibilidades históricas" (CONNELL, 2016, p. 199).

O capítulo nove também explora um assunto controverso: relação entre psiquiatria e transexualidade. Em "Excepcionalmente sãs: psiquiatria e mulheres transexuais" a cientista social faz uma retomada de diversas contribuições teóricas e expõe o caráter conservador e retrógrado que constituem as análises da psiquiatria e psicanálise sobre as pessoas transexuais. Algumas das abordagens médicas revelam um baixo teor científico que incorrem em hipóteses pouco fundamentadas, que reproduzem teses preconceituosas. As evidências apontadas pela medicina são frágeis, pois, segundo Colette Chiland (apud. CONNELL, 2016), as pessoas trans interrompiam o tratamento terapêutico que deveria ser de longo prazo. Isso ocorre em razão da condução das/dos profissionais que trabalhavam com a recuperação do gênero de nascimento, sem considerar a possibilidade de aceitação da nova identidade.

Diante desse cenário, as pessoas trans, em sua maioria, são marginalizadas e tornamse vulneráveis devido à negligência que sofrem do Estado. O processo de transição pode ser traumático se as mulheres transexuais não dispuserem de recursos financeiros para que tenham uma assistência especializada. É importante frisar que o acompanhamento

\footnotetext{
2 "Em alguns momentos, ela fala sobre os prazeres da feminilidade [...]. Contudo, com a mesma frequência, as práticas femininas parecem ser uma obrigação. Robyn vestiu saias mesmo quando dirigia o táxi - 'mesmo hoje não posso vestir calças, acho que são desconfortáveis... Tenho que usar vestidos e tenho que usar sapatos femininos'. Ela pintou as unhas mesmo tendo problemas médicos com elas, e está tentando voltar a usar saltos não obstante o problema no quadril [...] Resumidamente, ela se colocou num amplo treinamento para cuidados da aparência, e desenvolveu uma prática rotineira de se apresentar como mulher" (CONNELL, 2016, p. 183-184)
}

4 Revista Estudos Feministas, Florianópolis, 26(3): e53285 
psicológico e psiquiátrico seria de grande valia se informado por um viés feminista e crítico, como ocorre com a "psicologia da libertação" (CONNELL, 2016, p. 220).

Por fim, "Mulheres transexuais e o pensamento feminista" é o capítulo que encerra livro. Connell toma para si a difícil tarefa de promover diálogos substanciosos entre os feminismos e a causa trans. Tal empreendimento é, de certa forma, louvável: sua vida pessoal como mulher trans e sua carreira como pesquisadora de estudos de gênero se entrelaçam. Por esse viés, ela demonstra que, apesar das rusgas e divergências, é fundamental trazer as contradições para as discussões e trabalhar com elas.

Na década de 1990, a renúncia de um padrão dicotômico de gênero em que se questionava uma identidade fixa foi a ideia central que projetou Judith Butler e a Teoria Queer nos feminismos. Basicamente, a existência é estabelecida através das performances que subvertem as identidades de gênero conhecidas até então. Apesar da grande aceitação da Teoria Queer, emergiram diversos tensionamentos e críticas que demonstraram que o simples "alargamento" da noção de gênero não sintetiza o debate. O equívoco, apontado por diversas críticas feministas, dá-se na reiteração da questão identitária que acaba por negligenciar outras variáveis importantes e que afetam a vida das mulheres trans (pobreza e prostituição são apenas duas de uma sorte de situações de risco as quais estão submetidas). Assim, a associação de gênero à performance somente demonstra ser extremamente reducionista.

Connell procura demonstrar que há algumas incongruências no que concerne à transexualidade. Ela questiona, por exemplo, o fato de a militância trans estar presente na legenda LGBT quando o que está em pauta não é a orientação sexual, mas a identidade de gênero. Além disso, coloca em xeque inclusive o caráter fluído e abstrato que costuma ser associado ao gênero. Segundo ela, um approach que ofereça pouca centralidade a classe é deficitário. Há uma desigualdade abissal que separa, grosso modo, as mulheres que possuem condições de arcar com a cirurgia de redesignação daquelas que precisam se prostituir, contentar-se com sua aparência física ou, na pior das hipóteses, daquelas que se submetem a procedimentos de procedência duvidosa e altamente nocivos. Dessa maneira, a lógica capitalista encontra nas mulheres trans um nicho de mercado a ser explorado.

Connell destaca, então, que estamos diante de uma problemática social com reverberações políticas. As desigualdades de gênero, por exemplo, não são verificadas apenas durante a transição e na adoção de uma nova identidade, pois o processo será diferente para homens e mulheres transexuais, uma vez que as últimas "estão tirando os dividendos patriarcais que derivam dos homens como um grupo, nos mercados de trabalhos, mercados financeiros" (CONNELL, 2016, p. 244).

Nesse contexto, a autora aponta que, por questões estratégicas, é imprescindível promover aproximações entre as mulheres transexuais e os movimentos feministas. Ainda que a divisão não tenha sido superada, é importante considerar "a vida das mulheres transexuais como sendo inteligível nos termos feministas enquanto se mantenha fiel às experiências das mulheres transexuais" (CONNELL, 2016, p. 253).

O olhar crítico advindo de sua história de vida como pesquisadora e mulher transexual tornam as contribuições de Connell indispensáveis. As considerações finais do livro não indicam o encerramento do debate. As problemáticas estão em aberto e os conceitos em disputa. A partir de suas variadas referências, que possibilitaram uma abordagem multifocal das questões de gênero, a autora oferece subsídios de forma descomplicada e quase didática para quem busca compreender os principais debates e desdobramentos da temática. 
A aliança que Connell propõe entre as mulheres não está ancorada em ideias utópicas que pressupõem a homogeneização das identidades e suas demandas, pois busca evidenciar o caráter político que deve sublinhar os movimentos feministas. Diante disso, defende para que os feminismos sejam plurais e sensíveis às variações de nacionalidade, raça, classe e que explore experiências de mulheres diversas. As noções de reconhecimento e redistribuições teorizadas por Nancy Fraser e a solidariedade transnacional preconizada por Chandra Mohanty são os princípios fundamentais para a construção de uma "ordem de gênero mais justa" (CONNELL, 2016, p. 250).

\section{Referências}

CONNELL, Raewyn. Gênero em termos reais. Trad. de Marília Moschovich. São Paulo: nVersos, 2016.

SHOHAT, Ella. "Notes on the 'Post-colonial'". Social Text, n. 31/32, Third World and Post-Colonial Issues, p. 99-113, 1992.

[Recebida em 09/10/2017

e aceita em 20/02/2018]

Isabela Assunção de Oliveira Andrade'

'Universidade Federal de Pelotas, Programa de Pós-Graduação em Ciência Política,

Pelotas, RS, Brasil

Isabela Assunção de Oliveira Andrade (isabela.aoandrade@gmail.com) é Bacharel em Relações Internacionais pela Universidade Federal de Pelotas e mestranda em Ciência Política pela mesma instituição. Pesquisa especificamente pós-colonialismo e feminismos, e integra o grupo de pesquisa "O Giro Decolonial e a América Latina: contribuições para o debate global sobre as Teorias do Sul".

(iD) 0000-0001-8591-3674

6 Revista Estudos Feministas, Florianópolis, 26(3): e53285 